\title{
Formulation, optimization, and characterization of snakehead fish (Ophiocephalus Striatus) powder nanoemulgel
}

\author{
Robert Tungadi $^{\oplus}{ }^{*}$, Prisca Wicita ${ }^{1}$ \\ ${ }^{1}$ Pharmacy Department, Faculty of Sport and Health, State University of Gorontalo, Gorontalo, Indonesia
}

\begin{abstract}
The aim of the present study was to characterize and evaluate nanoemulgel of snakehead fish powder (SFP) for the poorly water-soluble drug. SFP was formulated into nanoemulsion utilizing the best comparison of surfactant, co-surfactant, and oil. Diverse nanoemulsion components (oil, surfactant, and co-surfactant) were chosen based on solvency and emulsification capacity. SFP $0.1 \%$ loaded nanoemulsion which tested by stress-stability testing which carried out for all formulations and those that passed these tests were characterized for droplet size, polydispersity index (PDI), zeta potential, $\mathrm{pH}$, viscosity, and transmittance. After that, nanoemulsion was added with $1.5 \%, 2.0 \%$, and $2.5 \%$ of HPMC in different concentrations and mixed until nanoemulgel form and evaluated for $\mathrm{pH}$, viscosity, spreadability, and extrudability measurement. The results of this research showed that SF nanoemulsion produced clear, stable, and transparent formula having the transmittance value $99.87 \%$. Mean droplet size and zeta potential of the optimized nanoemulsion (NE4) were found to be $98.6 \pm 0.93 \mathrm{~nm}$ (PDI $0.1 \pm 0.20$ ) and $-57.5 \pm 0.3 \mathrm{MV}$ respectively. Meanwhile, the evaluation results of nanoemulgel (NEG) showed $\mathrm{NEG}_{1.5}$ gave $\mathrm{pH}$ 6.0, viscosity $210 \mathrm{cP}$, spreadability $5.8 \mathrm{~g} \mathrm{~cm} / \mathrm{s}$ and extrudability $1.4 \mathrm{~g} / \mathrm{cm}^{2}$. Otherwise, $\mathrm{NEG}_{2.0}$ and $\mathrm{NEG}_{2.5}$ had high viscosity and $\mathrm{pH}$ generating low spreading on the skin i.e. $3.9 \mathrm{~g} \mathrm{~cm} / \mathrm{s}$ and $2.8 \mathrm{~g} \mathrm{~cm} / \mathrm{s}$ respectively. The results of the evaluation and preparation stability test showed a good level of stability of $\mathrm{NEG}_{1.5}$ with the viscosity and $\mathrm{pH}$ by one way ANOVA which did not change significantly.
\end{abstract}

Keywords: Nanoemulgel. Nanoemulsion. Powder. Particle size analyzer. Snakehead fish.

\section{INTRODUCTION}

In Indonesia, one of the freshwater fish species having the main function of human health is snakehead fish (Ophiocephalus striatus). It contains albumin, amino acids and unsaturated fatty acids which are often used by people to accelerate wound healing with the formation of new tissues (Mustard, 2013). Besides that, albumin in snakehead fish was utilized to accelerate burn wound healing, increase the amount of blood protein, improve fracture and prevent lung infection (Lawang, 2013).

According to Tungadi (2011), snakehead fish powder had been formulated into macroemulsion cream for accelerating wound healing of post-operation in vitro (Tungadi, 2011). In general, this cream was thermodynamically unstable which causes the formation of high surface free energy. This can be reduced by adding

\footnotetext{
*Correspondence: R. Tungadi. Pharmacy Department, Faculty of Sport and Health, State University of Gorontalo, Gorontalo, Indonesia, Jenderal Soedirman Street No. 6, Gorontalo 96128. Phone : +628124100360. E-mail: rtungadi@yahoo.com
}

surfactant and co-surfactant while the whole system generally tend to return to its most stable position, that is when the free energy is the lowest. Therefore, The reduction of particle size or droplet oil-water can be done by making nanoemulsion with the comparison of surfactant, co-surfactant, and oil appropriately (Devarajan, Ravichandran, 2011).

The snakehead fish powder can be formulated into emulgel dosage form because the contents of the fish consist of polar (water soluble protein) and nonpolar (fatty acid soluble oil) parts. Nanoemulgel can be used as transdermal drug delivery system which has to pay attention to penetration of drug active compounds because it has to be able to pass through the skin barrier i.e. stratum corneum.

Meanwhile, Tungadi and Hasan (2016) stated that snakehead fish cream (negative control) was difficult to penetrate stratum corneum using rabbits in vivo which could be seen open wound longer recovery than using penetrant enhancer such as propylene glycol (treatment group). This means that propylene glycol can accelerate 
the diffusion rate of albumin into stratum corneum which the amount of albumin around 50\% compared to without penetrant enhancer about 5-7\%. Therefore, SFP was formulated into nanoemulgel using the best comparison of surfactant (tween 80), co-surfactant (PEG 400) and oil (olive oil) appropriately. The characterization of snakehead fish powder nanoemulsion has important roles in showing stability measurements such as particle size, zeta potential, and poly-dispersion index by particle size analyzer (Tungadi, 2016).

Nanoemulgel consists of nanoemulsion and gel which can increase the diffusion rate of active compounds because it reduces the particle size or droplets from oil and water phase in the emulsion system. Smaller particle size can enhance extensive contact with the membrane cell particles and facilitate carrier particles for penetration into membrane cells. So, the amounts of drug active compounds were easy to penetrate systemic circulation which will increase the bioavailability of active compounds. This means that it does not need a penetrant enhancer to accelerate the diffusion rate of active compounds into membrane cells (Tungadi et al., 2018).

The formulation of snakehead fish powder used a low pressure homogenization method with comparison of surfactant, co-surfactant, and oil appropriately such as tween 80 , PEG 400 and olive oil. The characterization of snakehead fish powder nanoemulsion had important roles in showing stability measurements such as particle size, zeta potential, and polydispersity index by particle size analyzer. This can prove that snakehead fish powder, formulated into nanoemulsion utilizing low pressure homogenization method, can reduce the particle size of snakehead fish powder (Tungadi et al., 2019).

\section{MATERIAL AND METHODS}

\section{Material}

Snakehead fish powder of pharmaceutical grade was gained by Royal Medical Pharmaceutical, Indonesia, and was certified containing protein $85.6 \%$, albumin $30.2 \%$, omega-3 $2.03 \%$, omega- $2.11 \%$ and omega-9 $0.92 \%$ and polyunsaturated total $5.1 \%$ respectively. The gelling agent, HPMC 22.000, was purchased from Brataco Chemical. Basis of Nano-emulsion consisted of Tween 80 (surfactant), PEG 400 (Co-surfactant), and Olive oil (oil). All of them were bought from Intraco Chemical. DMDM Hydantoin and BHT were purchased from Sentana Chemical. The UV-Vis Spectrophotometry was from Perkin Elmer (USA). The Delsa ${ }^{\mathrm{TM}}$ Nano having particle size of $1 \mathrm{~nm}-700 \mathrm{~nm}$ (UK). In addition, a
pH meter (Systronics model EQMK), a sonicator (Specta Lab, model UC 40) and a hot air oven (Memmert) were utilized in this study.

\section{Formulation development of nanoemulsion}

\section{Optimization of gel basis}

HPMC solutions were made in different concentrations i.e. $1.5 \%, 2.0 \%$ and $2.5 \% \mathrm{w} / \mathrm{v}$ respectively. Each concentration of HPMC was weighed according to concentrations of each formula. After that, HPMC was dispersed into warm water $\left(70{ }^{\circ} \mathrm{C}\right)$ and allowed to stand for 15 minutes then stirred $500 \mathrm{rpm}$ for 3 minutes to form a clear gel with appropriate viscosity.

\section{Optimization of nanoemulsion basis}

The optimization of nanoemulsion basis was made in different comparisons of surfactant, co-surfactant and oil. There were 6 formulas with the different concentrations between surfactant (Tween 80), co-surfactant (PEG 400) and oil (olive oil) such as F1 (4:2:1), F2 (4:3:1), F3 (5:3:1), F4 (6:3:1), F5 (7:3:1), and F6 (7:4:1). Tween 80 and PEG 400 were mixed together utilizing magnetic stirrer for 30 minutes $250 \mathrm{rpm}$ (the first mixture). After that, olive oil was added to the first mixture while stirring and adding water drop by drop containing snakehead fish powder $0.1 \% \mathrm{w} / \mathrm{v}$ then done sonication for 10 minutes. The same procedure was made for all formulas with the different concentrations of tween 80, PEG 400, and olive oil.

\section{$\mathrm{pH}$, Viscosity and Transmittance}

The $\mathrm{pH}$ values for nanoemulsions were determined at $25^{\circ} \mathrm{C}$ by a calibrated $\mathrm{pH}$ meter (Systronics model EQMK, India). The viscosity of nanoemulsions was measured using viscometer Brookfield (DV-E Model, USA), equipped with a cone-plate type measuring system. The rheological studies were carried out at variable shear rates ranging from 1 to $100 \mathrm{~s}^{-1}$. The transmittance was observed by using Spectrophotometry UV-Vis (Perkin Elmer, USA) at $630 \mathrm{~nm}$. One milliliter of nanoemulsion formulation was taken in a test tube and water dilution was analysed at $630 \mathrm{~nm}$ in triplicate (Jain et al., 2013).

\section{Stability studies of nanoemulsion}

Nanoemulsions were assessed at accelerated conditions of storage with varying temperature and humidity, as per ICH guidelines (Guideline IHT, 2003). Nanoemulsions were placed in $5 \mathrm{~mL}$ glass vial, sealed and stored upright. Physical and chemical stabilities 
of nanoemulsions were evaluated for 3 months by storing them at three different temperature and humidity conditions $\left(25 \pm 2{ }^{\circ} \mathrm{C} / 60 \pm 5 \%\right.$ relative humidity (RH), $40 \pm 2{ }^{\circ} \mathrm{C} / 65 \pm 5 \% \mathrm{RH}$ and $\left.60 \pm 2{ }^{\circ} \mathrm{C} / 75 \pm 5 \% \mathrm{RH}\right)$ and then characterized at specific time intervals for various parameters (Shinde, 2013). The nanoemulsions were also visually observed for any signs of turbidity, phase separation, coalescence, and so on.

\section{CHARACTERIZATION AND EVALUATION}

\section{Preparation of nanoemulgel}

HPMC solution was made in different concentrations i.e. $1.5 \%, 2.0 \%$ and $2.5 \% \mathrm{w} / \mathrm{v}$ respectively. Each concentration of HPMC was weighed according to concentrations of each formula. After that, HPMC was dispersed into water and allowed to stand for overnight then stirred 500 RPM for 3 minutes to form a clear gel with appropriate viscosity and then the optimized nanoemulsion was incorporated into the gel base. The prepared nanoemulgel formulations were inspected visually for their color, appearance and consistency (Avadi et al., 2009).

\section{The particle size measurement of snakehead fish powder nanoemulgel}

Particle size, potential zeta, and polydispersity index by Dynamic Light Scattering (DLS) were measured from snakehead fish powder by putting nanoemulgel in the cuvette of DLS. Then this was measured by zeta sizer which is shown in graph (Avadi et al., 2009).

\section{Evaluation of nanoemulgel}

\section{Spreadability study}

Spreadability was determined by utilizing an apparatus suggested by Mutimer et al. There was a wooden block and a pulley attached to it at one end. On the basis of 'slip' and 'drag' characteristics of nanoemulgel, spreadability measurement was done. An excess of nanoemulgel $(\approx 2 \mathrm{~g})$ was placed between two uniform slides placed on the block, where one glass slide was fixed and another was attached to a pulley. On the top of the two slides, a $1 \mathrm{~kg}$ weight was placed for $5 \mathrm{~min}$ to provide a uniform film of the nanoemulgel between the slides. The time taken by the upper slide to move on the application of weight to it through the pulley was noted, and spreadability was calculated by using the following formula, in triplicate:

$$
\mathrm{S}=\mathrm{M} \times \mathrm{L} / \mathrm{T}
$$

S: Spreadability, M: Weight applied to upper slide, L: Length of the glass slide, T: Time taken to separate the slides completely from each other

\section{Extrudability study}

It is a test to measure the force required to extrude the gel from the tube. On the application of weight, the amount of gel extruded from the aluminium tube was determined. The nanoemulgel extruded should be at least $0.5 \mathrm{~cm}$ ribbon in $10 \mathrm{~s}$ (Nair et al., 2009). The higher the quantity of gel extruded, the better is the extrudability. The extrudability of each formulation was measured, in triplicate, and calculated by using the formula:

$$
\mathrm{E}=\mathrm{M} / \mathrm{A}
$$

E: Extrudability, M: Applied weight to extrude gel from tube, A: Area

\section{Stability studies of nanoemulgel}

Prepared nanoemulgels $(\approx 5 \mathrm{~g})$ were packed in aluminium collapsible tubes and kept for stability studies at $25 \pm 2{ }^{\circ} \mathrm{C} / 60 \pm 5 \% \mathrm{RH}, 40 \pm 2{ }^{\circ} \mathrm{C} / 65 \pm 5 \% \mathrm{RH}$ and $60 \pm 2{ }^{\circ} \mathrm{C} / 75 \pm 5 \% \mathrm{RH}$ for a period of 3 months, as per ICH guidelines (Khullar et al., 2012). At an interval of 15 days, samples were withdrawn and evaluated for physical appearance, $\mathrm{pH}$, viscosity, spreadability, and extrudability.

\section{RESULTS AND DISCUSSION}

\section{Optimization of gel basis}

The results of gel basis optimization in different concentrations i.e. HPMC $1.5 \%, 2 \%$, and $2.5 \% \mathrm{w} / \mathrm{v}$ respectively showed that HPMC $1.5 \% \mathrm{w} / \mathrm{v}$ gave the best result with clear physical appearance and appropriate viscosity (Table I).

HPMC $1.5 \% \mathrm{w} / \mathrm{v}$ as the gelling agent had low viscosity; so, that it was easy for snakehead fish powder to penetrate into skin cell membrane. Otherwise, the other concentrations had a high viscosity, which can affect snakehead fish powder penetration into skin cell membrane. This is in line with Leite-Silva et al. (2012) stated that the viscosity of a formulation can affect the permeation of active compounds into the skin which is directly related to the concentration of the a material's viscosity.

Meanwhile, Gallagher et al. (2003) studied the release of ketoprofen from a series of simple gels of increasing thickener content relative to solvent and its 
penetration into and through pig skin. While ketoprofen permeation and skin distribution was reduced as the viscosity of the gels increased, as expected, the authors showed that this could be attributed to increasing binding of the drug to the thickener, rather than to changes in viscosity (Leite-Silva et al., 2012).

In addition, Hidayah stated that HPMC had the ability to spread better than carbopol, methylcellulose, and sodium alginate which was also easy to apply to skin (Madan, Singh, 2010; Hidayah, 2013). Besides that, the advantages of HPMC were neutral, stable viscosity, resistant to microbial growth, clear gel and strong film on the dry skin (Angela, 2012).

TABLE I - The optimization result of gel basis

\begin{tabular}{lccc}
\hline Materials & F1 (\%) & F2 (\%) & F3 (\%) \\
\hline HPMC & 1.5 & 2 & 2.5 \\
Distilled Water & 100 & 100 & 100 \\
Observation & Clear & Clear & Clear \\
pH & 5.0 & 5.0 & 5.0 \\
Viscosity & $280.4 \mathrm{cP}$ & $458.5 \mathrm{cP}$ & $585.6 \mathrm{cP}$ \\
\hline
\end{tabular}

\section{Optimization of nanoemulsion basis}

The optimization of nanoemulsion basis indicated formula 6 with the comparison of olive oil, Tween 80 and PEG 400 (1:7:4). This had the best performance including viscosity, clarity, and stability (Table II).

Formula 6 was physically stable utilizing centrifugation method (3800 rpm; 5 hours). The formula did not segregate and clear solution (Figure 1). Otherwise, formulas 1 to 5 gave the cloudy appearance showing segregation after centrifugation. Tween 80 as nonionic surfactant has high hydrophilic and lipophilic balance (15) so that it can be stable in an emulsion system with oil in water
(Brandelero et al., 2010). This surfactant has pivotal roles in nanoemulsion basis because the surfactants can reduce interfacial surface tension causing the surfactant is absorbed on interface phase. Regarding this, it can decrease the surface free energy by ruining globule and resulting small globule (Natalia, 2012; Tungadi, 2018). The most surfactants are not able to reduce interfacial tension in emulsion so that it needs to add co-surfactant (PEG 400) which can increase the solubility of nonpolar groups (Swarbrick, 2007). Besides that, it can intensify flexibility of surfactant film and fluidity of emulsion phase (Arifianti, 2012).

We selected one nanoemulsion (F3-F6) which was the best ratio of the solubility of snakehead fish powder among surfactant, co-surfactant, and oil. The mean droplet sizes for the formulations NE1, NE2, NE3 and NE4 were found to be $654.6 \pm 2.8,240.8 \pm 2.5,368.3 \pm 1.8$ and $227.1 \pm 1.8 \mathrm{~nm}$ respectively (Table III). After running 3 cycles of low pressure homogenization at $500 \mathrm{rpm}$, mean droplet size was effectively reduced to $364.3 \pm 2.0$, $145.2 \pm 1.7,147.6 \pm 1.7$ and $98.6 \pm 0.86 \mathrm{~nm}$ for NE1, NE2, NE3 and NE4, respectively, having a polydispersity index (PDI) values of $0.22 \pm 0.08,0.20 \pm 0.01,0.20 \pm 0.20$ and $0.10 \pm 0.20$, respectively.

Nanoemulsions are kinetically stable systems and are formed by using a particular concentration of various components, with no sign of phase separation, creaming or cracking under various stress conditions. The most important feature of nanoemulsions is the mean droplet size, which must be in the nanometric range (Mahtab et al., 2016). The low pressure influence of magnetic stirrer can reduce droplet size of nanoemulsion to achieve the mean droplet size of less than $200 \mathrm{~nm}$, was studied.

\section{Characterization of nanoemulsion}

Based on the best result of nanoemulsion optimization, the smallest size and PDI, was NE4 is

TABLE II - The optimization result of nanoemulsion basis

\begin{tabular}{lcccccc}
\hline \multirow{2}{*}{ Materials } & \multicolumn{7}{c}{ Formula \% w/v } \\
\cline { 2 - 7 } & $\mathbf{F 1}$ & $\mathbf{F 2}$ & $\mathbf{F 3}$ & $\mathbf{F 4}$ & $\mathbf{F 5}$ & $\mathbf{F 6}$ \\
\cline { 2 - 7 } & $\mathbf{( 1 : 2 : 4 )}$ & $\mathbf{( 1 : 3 : 4 )}$ & $\mathbf{( 1 : 3 : 5 )}$ & $\mathbf{( 1 : 3 : 6 )}$ & $\mathbf{( 1 : 3 : 7 )}$ & $\mathbf{( 1 : 4 : 7 )}$ \\
\hline Olive oil & 5 & 5 & 5 & 5 & 5 & 5 \\
Tween 80 & 17 & 19.5 & 22 & 24.5 & 27.5 & 30 \\
PEG 400 & 13 & 15.5 & 18 & 20.5 & 22.5 & 25 \\
Distilled water & 100 & 100 & 100 & 100 & 100 & 100 \\
Observation & cloudy & cloudy & cloudy & cloudy & cloudy & clear \\
pH & 7.0 & 7.0 & 7.0 & 7.0 & 7.0 & 7.0 \\
\hline
\end{tabular}




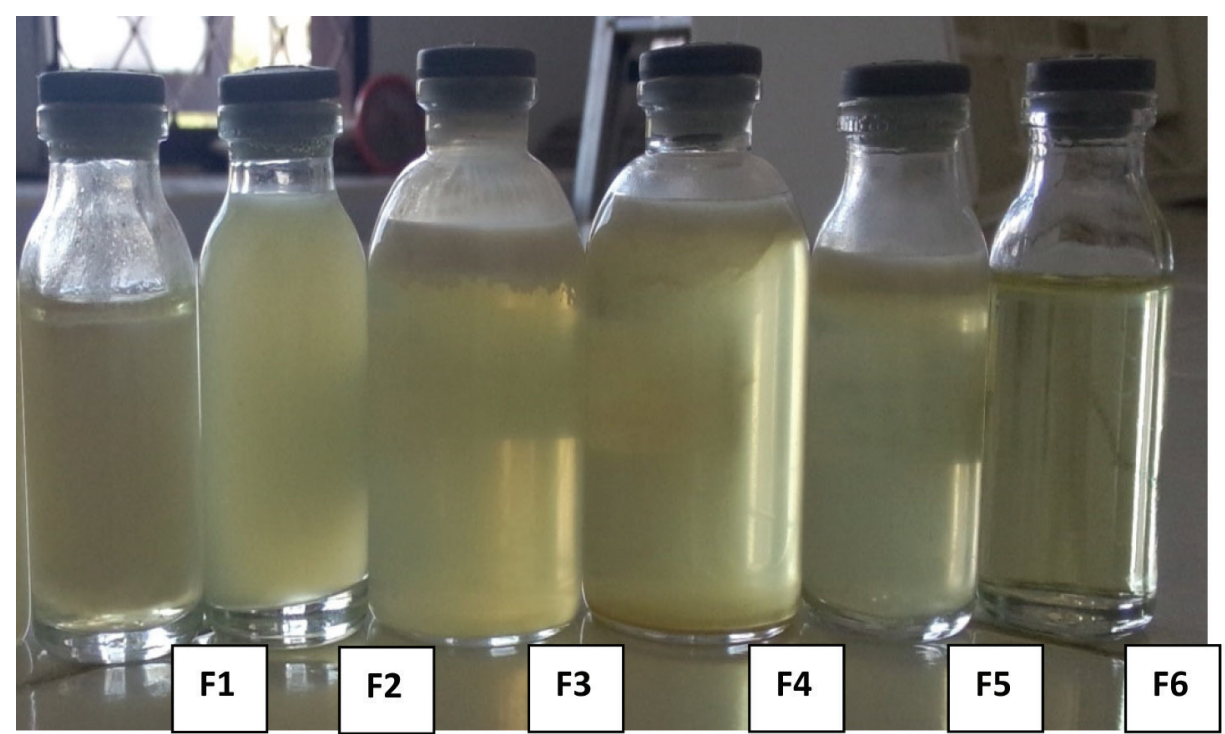

FIGURE 1 - The optimization result of nanoemulsion basis based on the solubility of snakehead fish powder among surfactant, co-surfactant, and oil.

TABLE III - Effect of low-pressure homogenization process variables on mean Droplet Size (DS) and Polydispersity Index (PDI) of various nanoemulsion formulations

\begin{tabular}{|c|c|c|c|c|c|c|c|c|}
\hline \multirow{4}{*}{ No. of cycles } & \multicolumn{8}{|c|}{ Formulations } \\
\hline & \multicolumn{2}{|c|}{ NE1 } & \multicolumn{2}{|c|}{ NE2 } & \multicolumn{2}{|c|}{ NE3 } & \multicolumn{2}{|c|}{ NE4 } \\
\hline & $\mathrm{DS} \pm \mathrm{SD}$ & $\mathrm{PDI} \pm \mathrm{SD}$ & $\mathrm{DS} \pm \mathrm{SD}$ & $\mathrm{PDI} \pm \mathrm{SD}$ & $\mathrm{DS} \pm \mathrm{SD}$ & $\mathrm{PDI} \pm \mathrm{SD}$ & $\mathrm{DS} \pm \mathrm{SD}$ & $\mathrm{PDI} \pm \mathrm{SD}$ \\
\hline & \multicolumn{2}{|c|}{$\mathrm{nm}$} & \multicolumn{2}{|c|}{$\mathrm{nm}$} & \multicolumn{2}{|c|}{$\mathrm{nm}$} & \multicolumn{2}{|c|}{$\mathrm{nm}$} \\
\hline C0 (crude) & $654.6 \pm 2.8$ & $0.38 \pm 0.02$ & $240.8 \pm 2.5$ & $0.1 \pm 0.01$ & $368.3 \pm 1.8$ & $0.2 \pm 0.09$ & $227.1 \pm 1.8$ & $0.2 \pm 0.17$ \\
\hline $\mathrm{C} 1$ & $564.8 \pm 2.4$ & $0.49 \pm 0.04$ & $206.4 \pm 1.4$ & $0.3 \pm 0.02$ & $256.5 \pm 3.5$ & $0.1 \pm 0.12$ & $105.5 \pm 0.4$ & $0.2 \pm 0.23$ \\
\hline $\mathrm{C} 2$ & $487.2 \pm 3.0$ & $0.50 \pm 0.15$ & $186.9 \pm 2.3$ & $0.5 \pm 0.02$ & $187.2 \pm 1.0$ & $0.1 \pm 0.21$ & $99.3 \pm 0.27$ & $0.2 \pm 0.12$ \\
\hline C3 & $364.3 \pm 2.0$ & $0.22 \pm 0.08$ & $145.2 \pm 1.7$ & $0.2 \pm 0.01$ & $147.6 \pm 1.7$ & $0.2 \pm 0.20$ & $98.6 \pm 0.86$ & $0.1 \pm 0.20$ \\
\hline
\end{tabular}

All values are reported as mean $\pm \mathrm{SD}(\mathrm{n}=3)$. C0: pre-homogenized nanoemulsion (crude nanoemulsion), PDI: polydispersity index, SD: Standard deviation.

having the average of zeta potential value after stability study around $-60.7 \pm 0.5 \mathrm{MV}$. Meanwhile, the $\mathrm{pH}$ values of nanoemulsion formulation before the stability test were found to be in the range of $5.0 \pm 0.48$ to $6.0 \pm 1.24$ (Table IV) The viscosities of nanoemulsion formulation, measured at a shear rate $100 \mathrm{~s}^{-1}$, were found the range between $140.7 \pm 0.33$ and $254.3 \pm 0.45 \mathrm{cP}$.

\section{Stability studies of nanoemulsion}

The stability studies showed that during the storage period of 3 months at $25 \pm 2{ }^{\circ} \mathrm{C} / 60 \pm 5 \% \mathrm{RH}, 40 \pm 2{ }^{\circ} \mathrm{C} / 65 \pm 5 \%$ $\mathrm{RH}$ and $60 \pm 2{ }^{\circ} \mathrm{C} / 75 \pm 5 \% \mathrm{RH}$, optimized nanoemulsion (NE4) described very negligible changes in mean droplet size, zeta potential, $\mathrm{PDI}, \mathrm{pH}$, viscosity, and transmittance

TABLE IV - Determination of $\mathrm{pH}$, viscosity and transmittance of various nanoemulsion formulations

\begin{tabular}{lcccc}
\hline Formulation Code & Smix ratio & pH & V(cP) & t (\%) \\
\hline NE1 & $1: 3: 5$ & $5.5 \pm 0.43$ & $254.3 \pm 0.45$ & $98.76 \pm 0.02$ \\
NE2 & $1: 3: 6$ & $5.0 \pm 0.48$ & $208.2 \pm 0.76$ & $97.78 \pm 0.19$ \\
NE3 & $1: 3: 7$ & $6.0 \pm 0.19$ & $155.8 \pm 0.38$ & $98.46 \pm 0.15$ \\
NE4 & $1: 4: 7$ & $6.0 \pm 1.24$ & $140.7 \pm 0.33$ & $99.87 \pm 0.05$ \\
\hline
\end{tabular}

All values are reported as mean $\pm \mathrm{SD}(\mathrm{n}=3)$. V: viscosity, cP: centipoise, $\mathrm{t}$ : transmittance. 
(Table V). The results gave no phase separation and flocculation, proving its stable nature. At the end of three months, the drug content was assayed and was found to be $>90 \%$ of the initial drug added, showing the chemical stability of the system during the storage period.

Furthermore, the origin of the negative zeta potential of nominations might be due to preferential adsorption or desorption of electrolyte ions on the surface (Leser et al., 2006). With increasing the concentration of tween 80 , an increase in the negative value of zeta potential might be associated with the presence of impurities, i.e. peroxides, free fatty acids and so on (Delgado, 2001).

Besides that, small particle size formulation yet concerned when delivering drugs through the skin, the rheology properties of nanoemulsion is imperative. The nanoemulsion formulation, it may be not advantageous to make utilized because of low viscosity and spreadability. Therefore, the approach of incorporation of nanoemulsion with gelling system can help in overcoming this problem.

\section{Evaluation of nanoemulgel}

The $\mathrm{pH}$ values for $\mathrm{NEG}_{1.5}, \mathrm{NEG}_{2.0}$ and $\mathrm{NEG}_{2.5}$ were found to be in the range of $6.2 \pm 0.45$ to $6.5 \pm 0.55$ (Table VI). Viscosities for $\mathrm{NEG}_{1.5}, \mathrm{NEG}_{2.0}$ and $\mathrm{NEG}_{2.5}$ were found to be $258 \pm 3.76,558 \pm 5.20$ and $865 \pm 3.53 \mathrm{cP}$, respectively. Furthermore, spreadability values for $\mathrm{NEG}_{1.5}, \mathrm{NEG}_{2.0}$ and $\mathrm{NEG}_{2.5}$ were found to be about $6.8 \pm 0.23,4.9 \pm 0.25$ and $2.8 \pm 0.56 \mathrm{~cm}$, respectively (Table VI). Extrudabilities of $\mathrm{NEG}_{1.5}, \mathrm{NEG}_{2.0}$ and $\mathrm{NEG}_{2.5}$ were found to be $2.4 \pm 0.56$, $3.6 \pm 0.65$ and $5.0 \pm 0.78 \mathrm{~cm}$, respectively, in $10 \mathrm{~s}$ on applying a weight of $400 \mathrm{~g}$ (Table VI). In assessing spreadability and extrudability values of nanoemulgel formulation, $\mathrm{NEG}_{1.5}$ was found to be $0.76 \pm 0.05 \%$ (w/w). $\mathrm{NEG}_{1.5}$ was found to be stable during three months storage period at different conditions of temperature and humidity. There was no change in physical appearance, $\mathrm{pH}$ and viscosity (data not shown).

Meanwhile, the statistical analysis of freeze-thaw method particularly $\mathrm{pH}$ and viscosity (Table VI) data showed that $\mathrm{P}$ value is greater than 0.05 which mean there is no real difference between $\mathrm{pH}$ and viscosity of the stability test. It means that there were no significant changes by one-way ANOVA test.

The particle size of snakehead fish powder, containing albumin, protein, and amino acids, was used in the formulation, was $30 \mu \mathrm{m}$. It means that the particle size of powder has important roles in accelerating drug diffusion to penetrate into membrane cell. Therefore, the snakehead fish powder was formulated into nanoemulgel to reduce the particle size of powder using a low energy homogenization method. Due to the small particle size from the emulsion, the powder can accelerate active compounds such as albumin, protein, and amino acids to penetrate membrane cells. It causes the increase of the contact area between the carrier particles and the membrane cell (Ariviani, 2015). Regarding this, the carrier particles are easy to release active compounds into systemic circulation system causing the increase of bioavailability of snakehead fish nanoemulgel and the acceleration of wound healing processes.

Among different nanoemulgels, $\mathrm{NEG}_{1.5}$ was found to be a creamy and viscous preparation having a smooth homogenous texture, glossy appearance and no sign of phase separation. Whereas $\mathrm{NEG}_{2.0}$ and $\mathrm{NEG}_{2.5}$ was too viscous and turbid in appearance based on visual appearance and viscosity.

TABLE V - Stability study of Optimized Nanoemulsion (NE4)

\begin{tabular}{lccccccc}
\hline $\mathbf{T}\left({ }^{\circ} \mathbf{C}\right) / \mathbf{R H}(\%)$ & Time (days) & $\begin{array}{c}\text { Mean (nm) } \\
\text { droplet size }\end{array}$ & $\begin{array}{c}\text { Zeta }(\mathbf{m V}) \\
\text { potential }\end{array}$ & PDI & $\mathbf{p H}$ & $\mathbf{V}(\mathbf{c P})$ & $\mathbf{t}(\mathbf{\%})$ \\
\hline \multirow{2}{*}{$25 \pm 2 / 60 \pm 5$} & 30 & $120.3 \pm 2.2$ & $-38.3 \pm 0.8$ & $0.34 \pm 0.03$ & $6.8 \pm 0.22$ & $150.7 \pm 1.25$ & $99.28 \pm 0.18$ \\
& 60 & $135.8 \pm 3.1$ & $-55.9 \pm 0.6$ & $0.55 \pm 0.05$ & $6.0 \pm 0.32$ & $178.5 \pm 1.85$ & $96.35 \pm 0.19$ \\
& 90 & $100.5 \pm 2.0$ & $-38.3 \pm 0.4$ & $0.28 \pm 0.02$ & $6.2 \pm 0.18$ & $180.2 \pm 1.23$ & $97.24 \pm 0.45$ \\
\hline \multirow{3}{*}{$40 \pm 2 / 65 \pm 5$} & 30 & $140.7 \pm 3.0$ & $-20.5 \pm 0.2$ & $0.33 \pm 0.08$ & $5.7 \pm 0.24$ & $188.5 \pm 2.37$ & $98.20 \pm 0.65$ \\
& 60 & $98.32 \pm 5.1$ & $-45.6 \pm 0.1$ & $0.57 \pm 0.05$ & $5.6 \pm 0.18$ & $140.5 \pm 1.89$ & $95.58 \pm 0.49$ \\
& 90 & $85.48 \pm 3.6$ & $-60.4 \pm 0.8$ & $0.28 \pm 0.09$ & $5.2 \pm 0.27$ & $150.8 \pm 1.20$ & $97.24 \pm 0.38$ \\
\hline \multirow{3}{*}{$60 \pm 2 / 75 \pm 5$} & 30 & $78.44 \pm 5.2$ & $-47.5 \pm 0.8$ & $0.37 \pm 0.02$ & $5.4 \pm 0.26$ & $137.6 \pm 1.98$ & $99.25 \pm 0.29$ \\
& 60 & $79.57 \pm 3.7$ & $-53.3 \pm 0.4$ & $0.32 \pm 0.01$ & $5.6 \pm 0.20$ & $178.2 \pm 2.54$ & $98.65 \pm 0.36$ \\
& 90 & $99.90 \pm 2.7$ & $-60.7 \pm 0.5$ & $0.28 \pm 0.09$ & $5.5 \pm 0.45$ & $157.8 \pm 2.16$ & $97.34 \pm 0.76$ \\
\hline
\end{tabular}

All values are reported as mean $\pm \mathrm{SD}(\mathrm{n}=3)$. T:temperature, $\mathrm{PDI}$ : poly-dispersity index, V: viscosity, cP: centripoise, t: transmittance. 
TABLE VI - Composition and evaluation parameters of nanoemulgel

\begin{tabular}{|c|c|c|c|}
\hline & $\mathrm{NEG}_{1.5}$ & $\mathbf{N E G}_{2.0}$ & $\mathrm{NEG}_{2.5}$ \\
\hline \multicolumn{4}{|l|}{ Composition } \\
\hline Snakehead fish powder $(\% \mathrm{w} / \mathrm{w})$ & 0.125 & 0.125 & 0.125 \\
\hline HPMC $22000(\% w / v)$ & 1.5 & 2.0 & 2.5 \\
\hline Tween $80(\% w / w)$ & 32.5 & 32.5 & 32.5 \\
\hline PEG $400(\% \mathrm{w} / \mathrm{w})$ & 27.5 & 27.5 & 27.5 \\
\hline Olive oil $(\% \mathrm{w} / \mathrm{w})$ & 5 & 5 & 5 \\
\hline BHT $(\% w / v)$ & 0.1 & 0.1 & 0.1 \\
\hline DMD Hydantoin (\%w/v) & 0.1 & 0.1 & 0.1 \\
\hline Water & q.s. & q.s. & q.s. \\
\hline \multicolumn{4}{|l|}{ Evaluation parameters } \\
\hline$\overline{\mathrm{pH}^{*}}$ & $6.2 \pm 0.45$ & $6.5 \pm 0.55$ & $6.2 \pm 0.52$ \\
\hline Viscosity $(\mathrm{cP})^{*}$ & $258 \pm 3.76$ & $558 \pm 5.20$ & $865 \pm 3.53$ \\
\hline Spreadability $(\mathrm{g} \mathrm{cm} / \mathrm{s})$ & $6.8 \pm 0.23$ & $4.9 \pm 0.25$ & $2.8 \pm 0.56$ \\
\hline Extrudability $\left(\mathrm{g} / \mathrm{cm}^{2}\right)$ & $2.4 \pm 0.56$ & $3.6 \pm 0.65$ & $5.0 \pm 0.78$ \\
\hline
\end{tabular}

All values are reported as mean $\pm \mathrm{SD}(\mathrm{n}=3)$. q.s.: quantity sufficient, $\mathrm{cP}$ : centipoise, g: gram, cm: centimeter, s: second. $* \mathrm{P}>0.05$; One Way ANOVA Test, the value of P or Sig. 1 which means bigger than $\alpha 0.05$.

\section{CONCLUSION}

It can be concluded that all of the evaluation results and stability tests showed snakehead fish nanoemulgel $\left(\mathrm{NEG}_{1.5}\right)$ has good stability including the characterization of snakehead fish nanoemulgel.

\section{CONFLICTS OF INTEREST}

The authors report no conflicts of interest. The authors alone are responsible for the content and writing of the paper.

\section{ACKNOWLEDGMENTS}

The authors are thankful to The Ministry of Research, Technology, and Higher Education of Indonesia, which has funded this research by grant competition (decentralization grant) and are also thankful to PT. Royal Medical, Pharmaceuticals, Indonesia, for providing snakehead fish powder for this work and PT. NanoTech Herbal Indonesia, LIPI Serpong, Indonesia gives technical supports.

\section{REFERENCES}

Avadi MR, Sadeqhi MN, Abedin S, Atyabi F, Dinarvand R, Tehrani RM. Preparation and characterization of insulin nanoparticles using chitosan and arabic gum with ionic gelation method. Nanomed J. 2009;6(1):58-63.
Angela L. Antioxidant activity and stability of anti-aging gel containing potato (Solanum tuberosum L) water extract. Department of Pharmacy. Indonesia University. Depok; 2012.

Arifianti AE. The stability and antioxidant activity test of nanoemulsion of black cumin seed oil (Nigella sativa Linn Seed Oil) as neutraceutical. Pharmacy Department. Indonesia University. Depok; 2012.

Ariviani S, et al. Formulation and stabilization of emulsion O/W of VCO and palm oil using spontaneous emulsion method. J Nat Agric. 2015;9(6):10-16.

Brandelero RPH, Yamashita F, Grossmann MVE. The effect of surfactant tween 80 on the hydrophilic water vapor permeation, and the mechanical properties of cassava starch and poly (butylenes adipate-co-terephtalate) (PBAT) blend films. Carbohydr Pol J. 2010;82(4):1102-09.

Devarajan V, Ravichandran V. Nanoemulsions: as modified drug delivery tool. Int J Comprehens Pharm. 2011;2(4):1-5.

Delgado ÁV. Interfacial electrokinetics and electrophoresis. CRC Press; 2001.

Gallagher SJ, Trottet L, Heard CM. Ketoprofen: release from, permeation across and rheology of simple gel formulations that simulate increasing dryness. Int J Pharm. 2003;268(1-2):37-45. 
Guideline IHT. Stability testing of new drug substances and products. Q1A (R2), Curr Step. 2003; 4.

Hidayah U. The formulation of Pegagan Herb (Centella asiatica L. Urban) extract gel using HPMC SH 60 as gelling agent and the test of burn wound on rabbits skin. Indonesia University; 2013.

Jain K, Kumar RS, Sood S, Gowthamarajan K. Enhanced oral bioavailability of atorvastatin via oil-in-water nanoemulsion using aqueous titration method. J Pharm Sci Res. 2013;5(1):1825 .

Khullar R, Kumar D, Seth N, Saini S. Formulation and evaluation of mefenamic acid emulgel for topical delivery. Saudi Pharm J. 2012;20(1):63-7.

Lawang AT. The Making of snakehead fish (Ophiocepahalus striatus) concentrate dispersion as food supplement. The Agriculture Faculty. Hasanuddin University. Makassar; 2013.

Leite-Silva VR, Almeida MM, Fradin A, Grace JE, Robert MS. Delivery of drugs applied topically to the skin. Expert Rev Dermatol. 2012;7(4):383-397.

Leser ME, Sagalowicz L, Michel M, Watzke HJ. Self-assembly of polar food lipids. Adv Colloid Inter Sci. 2006;123-126:12536.

Madan J, Singh R. Formulation and evaluation of Aloe vera gels. Int J Pharm Sci. 2010;2(10):1588.

Mustard. The study of making shredded snakehead fish (Ophiochepalus striatus) as food suplement. The Knowledge of Food Technology. Hasanuddin University. Makassar; 2013.

Mahtab A, Anwar M, Mallick N, Naz Z, Jain GK, and Ahmad FJ. Transungual delivery of ketoconazole nanoemulgel for the effective management of onychomycosis. AAPS PharmSciTech. 2016;17(6):1477-90.
Natalia M. The stability and antibacterial activity test of black cumin oil (Nigella sativa L.) nano-emulsion gel (Nanoemulgel). Pharmacy Department. Indonesia University. Depok; 2012.

Nair AB, Kim HD, Chakraborty B, Singh J, Zaman M, Gupta A, et al. Ungual and trans-ungual iontophoretic delivery of terbinafine for the treatment of onychomycosis. J Pharm Sci. 2009;98(11):4130-40.

Swarbrick J. Encyclopedia of Pharmaceutical Technology. $3^{\text {rd }}$ ed. Volume 1. New York: Informa Healthcare USA; 2007.

Shinde PB. Component screening of miconazole nitrate nanoemulsion. Asian J Biomed Pharm Sci. 2013;3(19):33-40.

Tungadi R. The acceleration of wound healing of snakehead fish cream towards rabbit's skin wound histopathologically. Indo Pharm J. 2011;9(2):91-7.

Tungadi R, Abdulkadir W, Ischak N, Rahim B. Liposomal formulation of snakehead fish (Ophiocephalus striatus) powder and toxicity study in zebrafish (danio rerio) model. Pharm Sci. 2019;25(2):145-53.

Tungadi R, Hasan MA. The effect of penetrant enhancer combination towards the diffusion rate of snakehead fish (Ophiocephalus striatus) cream in vitro and vivo. Int $\mathrm{J}$ PharmTech Res. 2016;9(6):508-13.

Tungadi R, Imran A.K. Formulation development and characterization of snakehead fish powder in oral double emulsion. Int J App Pharm. 2018;10(2):70-75.

Tungadi R, Susanty W, Wicita P, Pido E. Transdermal delivery of snakehead fish (Ophiocephalus striatus) nanoemulgel containing hydrophobic powder for burn wound. Pharm Sci. 2018;24(4):313-23.

Received for publication on $07^{\text {th }}$ June 2017 Accepted for publication on $02^{\text {nd }}$ December 2018 